\title{
Value of plasma SN-38 levels and DPD activity in irinotecan-based individualized chemotherapy for advanced colorectal cancer with heterozygous type UGTIAI*6 or UGTIAI*28
}

This article was published in the following Dove Press journal: Cancer Management and Research

\begin{abstract}
Chuan Tian, ${ }^{1,2, *}$ Haifeng Ying, ${ }^{3, *}$ Rongyuan Zhuang, ${ }^{4}$ Xiaowei Zhang, ${ }^{5}$ Hongmin Lu, ${ }^{6}$ Hui Wang, ${ }^{7}$ Shuowen Wang, ${ }^{8} \mathrm{Qi} \mathrm{Li}$, Chungang Wang, ${ }^{9}$ Xun Cai
\end{abstract}

'Department of Oncology, Shanghai General Hospital, Shanghai Jiaotong University School of Medicine, Shanghai 200080 , People's Republic of China; ${ }^{2}$ Department of Medical Oncology, Jinling Hospital, School of Medicine, Nanjing University, Nanjing 210002, People's Republic of China; ${ }^{3}$ Department of Traditional Chinese Medicine, Ruijin Hospital, Medical College, Shanghai Jiaotong University, Shanghai 200025, People's Republic of China; ${ }^{4}$ Department of Oncology, Zhongshan Hospital, Shanghai Medical College, Fudan University, Shanghai 200032, People's Republic of China; ${ }^{5}$ Department of Medical Oncology, Shanghai Cancer Center Shanghai Medical College, Fudan University, Shanghai 200032, People's Republic of China; ${ }^{6}$ Department of Oncology, Renji Hospital, Medical College, Shanghai Jiaotong University, Shanghai 200I27, People's Republic of China; 'Department of Oncology, Shanghai Tenth People's Hospital, Shanghai Tongji University, Shanghai 200072, People's Republic of China; ${ }^{8}$ Department of Clinical Pharmacy, Shanghai General Hospital, Shanghai Jiaotong University School of Medicine, Shanghai 200080, People's Republic of China; ${ }^{9}$ Department of Radiotherapy, Shanghai General Hospital, Shanghai Jiaotong University School of Medicine, Shanghai 200080, People's Republic of China

*These authors contributed equally to this work

Correspondence: Xun Cai

Department of Oncology, Shanghai General Hospital, Shanghai Jiaotong University School of Medicine, 100 Haining Road, Hongkou District, Shanghai 200080, People's Republic of China

Tel +86 I39 |732066|

Fax +86 63069779

Email caixuncn@163.com
Purpose: The relationship between the pharmacokinetics of irinotecan and outcomes of advanced colorectal cancer is unclear, and few studies have examined individualized irinotecanbased chemotherapy depending on plasma 7-ethyl-10-hydroxy camptothecin ( $\mathrm{SN}-38)$ levels and dihydropyrimidine dehydrogenase (DPD) activity, particularly for the UGT1A1*6 or UGT1A1*28 heterozygous type.

Methods: This study retrospectively explored the relationship among plasma SN-38 level 1.5 hours after critical enzyme for irinotecan (CPT-11) administration $\left(\mathrm{C}_{\mathrm{SN}-38 \text { 1.5h }}\right)$, plasma $\mathrm{SN}-38$ level 49 hours after CPT-11 administration $\left(\mathrm{C}_{\mathrm{SN}-3849 \mathrm{~h}}\right)$, DPD activity, and clinical outcomes for the UGT1A $1 * 6$ and UGT1A $1 * 28$ heterozygous types.

Results: $\mathrm{C}_{\mathrm{SN}-381.5 \mathrm{~h}}$ and $\mathrm{C}_{\mathrm{SN}-3849 \mathrm{~h}}$ of the UGT1A1*6 or UGT1A1*28 heterozygous type were close to those of UGT1A $1 * 6$ and UGT1A $1 * 28$ wild-types; some of those with relatively high $\mathrm{C}_{\mathrm{SN}-381.5 \mathrm{~h}}$ levels obtained better median progression-free survival (mPFS), whereas others with higher $\mathrm{C}_{\mathrm{SN}-3849 \mathrm{~h}}$ concentrations showed a relatively high incidence of adverse reactions possibly because of the decreased activity of DPD.

Conclusion: Increasing the dosage of CPT-11 according to $\mathrm{C}_{\mathrm{SN}-381.5 \mathrm{~h}}$ may improve the efficacy in patients with lower $\mathrm{C}_{\mathrm{SN}-381.5 \mathrm{~h}}$ levels. For cases with comparably low DPD activity, advisable primary and subsequent dose adjustment of 5-fluorouracil based on plasma 5-fluorouracil levels may be a practical strategy for reducing the occurrence of adverse reactions for personalized treatment of the UGT1A $1 * 6$ or UGT1A $1 * 28$ heterozygous type.

Keywords: irinotecan, pharmacokinetics, enzyme activity, uridine diphosphate glucuronosyltransferase 1A1, colorectal cancer

\section{Introduction}

Single-nucleotide polymorphisms (SNPs) in drug metabolizing enzymes have an considerable effect on drug absorption, metabolism, distribution, and excretion and can lead to completely different efficacies and/or adverse reactions (ADRs). ${ }^{1,2}$ Uridine diphosphate glucuronosyltransferase 1A1 (UGT1A1), which converts 7-ethyl-10-hydroxy camptothecin (SN-38) to SN-38 glucuronide (SN-38G), is a critical enzyme for irinotecan (CPT-11), which is the first-line drug for treating metastatic colorectal cancer (mCRC). Previous studies demonstrated that the incidence of life-threatening ADRs is often linked to mutant homozygotes in UGT1A $1 * 6$ and $* 28$, which reduce or inhibit UGT1A1 activity and increase plasma SN-38 concentrations; ${ }^{3,4}$ however, the incidence of the homozygous genotype is $<10 \%$ in Asian population., ${ }^{5,6}$ Thus, in addi- 
tion to screening for homozygous genotypes that may cause serious ADRs, the main purpose of CPT-11 individualized therapy for these patients is to elucidate whether the pharmacokinetics of CPT-11 is correlated with clinical outcomes so that the dose can be adjusted within a relatively short period to achieve better results.

There may be a widely variable range of UGT1A1 activity for UGT1A $1 * 6$ and/or *28 heterozygous types (including $* 1 / * 28-* 1 / * 1, * 1 / * 1-* 1 / * 6$, and $* 1 / * 28-* 1 / * 6$ genotypes). Theoretically, to achieve personalized administration, the best strategy is to relate CPT-11 pharmacokinetics parameters with the UGT1A $1 * 6$ and *28 genotypes, rather than relying on one factor. ${ }^{7}$ However, the relationship between plasma SN-38 levels or concentration-time curve (area under the curve [AUC]) and clinical efficacy remains unclear, which may be related to the different distribution of UGT1A $1 * 28$ and UGT1A $1 * 6$ genotypes between population and poor clinical operations of calculating SN-38/SN-38G AUC for the following CPT-11 dosage. Thus, the maximum tolerance dose (MTD) is determined only by dose escalation. ${ }^{8,9}$ Our previous studies showed that plasma SN-38 level 1.5 hours after CPT-11 administration $\left(\mathrm{C}_{\mathrm{SN}-381.5 \mathrm{~h}}\right)$ was related to progression-free survival (PFS) for UGT1A $1 * 6$ and $* 28$ wild-types and to better clinical efficacy for relatively high $\mathrm{C}_{\mathrm{SN}-381.5 \mathrm{~h}{ }^{10,11}}$

In addition, CPT-11 is routinely combined with 5-fluorouracil $(5-\mathrm{FU})$ as a first-line treatment for $\mathrm{mCRC}$, and $80 \%-85 \%$ of $5-\mathrm{FU}$ is metabolized to inactive dihydro fluorouracil (DHFU) by dihydropyrimidine dehydrogenase (DPD) in the liver. Serious ADRs such as neutropenia, diarrhea, and oral mucositis, which are similar to those caused by CPT-11, occur in cases of partial or total deficiency of DPD activity, leading to inhibition of plasma 5-FU clearance; ${ }^{12}$ accordingly, the identification of CPT-11-associated ADRs may be affected. Therefore, it is important to detect DPD activities before FOLFIRI chemotherapy, which can reduce the probability of 5-FU-related ADRs by decreasing the 5-FU dosage for those with lower DPD activities to improve the effectiveness of CPT-11 individualized medication.

Assessing the SNPs UGT1A1*6 and *28 and DPD activities simultaneously is a feasible strategy for dosage personalization of CPT-11, although few studies have examined this approach. ${ }^{13}$ Thus, we retrospectively explored the correlation between clinical parameters such as $\mathrm{C}_{\mathrm{SN}-381.5 \mathrm{~h}}$, plasma $\mathrm{SN}-38$ level 49 hours after CPT-11 administration $\left(\mathrm{C}_{\mathrm{SN}-3849 \mathrm{~h}}\right)$, DPD activity, and outcomes (efficacy and ADRs) to provide a basis for individualized CPT-11 administration according to plasma SN-38 levels and DPD activity for patients with the UGT1A $1 * 28$ or $* 6$ heterozygous genotypes.

\section{Methods}

\section{Patient's eligibility}

The SNPs of UGT1A $1 * 6$ and * 28 were detected in 550 cases before the first chemotherapy treatment from December 2012 to May 2014, and 499 cases met the following inclusion criteria: previously untreated local advanced or mCRC with measurable lesions verified by pathological and imaging data, East Cooperative Oncology Group (ECOG) physical status score of 0-2 points, life expectancy greater than 3 months, no chemotherapy contraindication, written informed consents, serum bilirubin levels, and transaminase levels limited to 1.5and 5-fold the normal levels, and ability to undergo administration of at least three cycles of FOLFIRI chemotherapy, as well as one assessment. Patients with complete or incomplete intestinal obstruction, chronic enteritis, a history of extensive colectomy, severe allergy to CPT-11 or 5-FU, other malignant tumors and central nervous system metastases, previously treated measurable lesions such as by radiotherapy or local interventional therapy, major organ dysfunction, and poor compliance and pregnancy were ruled out. A total of 234 cases confirmed with UGT1A $1 * 28$ and/or *6 heterozygous genotype were analyzed, which include those from the Zhongshan Hospital (54 cases), Cancer Medical Center (43 cases) affiliated with Fudan University Shanghai Medical College, Ruijin Hospital (41 cases), Renji Hospital (36 cases), and General Hospital (30 cases) affiliated with Shanghai Jiaotong University Medical of School and Shanghai Tenth People's Hospital (20 cases) affiliated with Tongji University (Table 1).

\section{SNPs analysis for UGTIAI}

Plasma genomic DNA was collected using a DNA purification kit (Qiagen, Hilden, Germany), and gene fragments containing UGT1A $1 * 6$ and $* 28$ polymorphism sites were amplified by PCR $(25 \mu \mathrm{L}): 2 \mu \mathrm{L}$ of $10 \times$ PCR buffer $\left(15 \mathrm{mM} \mathrm{MgCl}_{2}\right), 2 \mu \mathrm{L}$ of dNTP $(2.5 \mathrm{mM}), 0.5 \mu \mathrm{L}$ of sense and antisense primers $(10 \mu \mathrm{M}), 0.2$ $\mu \mathrm{L}$ of Taq DNA polymerase $(5 \mathrm{U} / \mu \mathrm{L}), 1 \mu \mathrm{L}$ of DNA templates, and $18.8 \mu \mathrm{L}$ of double-distilled water $\left(\mathrm{ddH}_{2} \mathrm{O}\right)$. The primer pairs for * 6 and $* 28$ polymorphism points in the UGT1A1 gene were designed as follows: upstream, $5^{\prime}$-TCCCTGCTACCTTTGTGGAC-3'; downstream, 5'-AGCAGGCCCAGGACAAGT-3'. The conditions of PCR amplification were as follows: initial denaturation at $94^{\circ} \mathrm{C}$ for 5 minutes, followed by 40 cycles of denaturation at $94^{\circ} \mathrm{C}$ for 15 seconds, annealing at $55^{\circ} \mathrm{C}$ for 25 seconds, extension at $72^{\circ} \mathrm{C}$ for 50 seconds, and then extension at $72^{\circ} \mathrm{C}$ for 7 minutes. Next, $5 \mu \mathrm{L}$ of eligible PCR samples 
Table I Clinical characteristics between UGTIAI*28 and *6 heterozygous genotypes

\begin{tabular}{|c|c|c|c|c|}
\hline $\begin{array}{l}\text { Clinical } \\
\text { characteristics }\end{array}$ & $\begin{array}{l}*|/ * 28-*| / * I \\
\text { genotype } \\
(\mathrm{n}=98)\end{array}$ & $\begin{array}{l}* I / * 1-* 1 / * 6 \\
\text { genotype } \\
(n=116)\end{array}$ & $F$ & $P$ \\
\hline $\begin{array}{l}\text { ECOG } \\
\text { performance } \\
\text { score }\end{array}$ & & & 0.10 & 0.75 \\
\hline 0 & 52 & 59 & & \\
\hline 1 & 46 & 57 & & \\
\hline Gender & & & 2.39 & 0.12 \\
\hline Male & 61 & 60 & & \\
\hline Female & 37 & 56 & & \\
\hline $\begin{array}{l}\text { Median age } \\
\text { (years) }\end{array}$ & 55.55 & 54.90 & 0.03 & 0.87 \\
\hline $\begin{array}{l}\text { Primary tumor } \\
\text { site }\end{array}$ & & & 1.76 & 0.19 \\
\hline Colon & 46 & 65 & & \\
\hline Rectum & 52 & 51 & & \\
\hline TMN staging & & & 0.01 & 0.91 \\
\hline $\mathrm{Illb}$ & 8 & 9 & & \\
\hline IV & 90 & 107 & & \\
\hline $\begin{array}{l}\text { Metastatic } \\
\text { organs }\end{array}$ & & & 0.95 & 0.62 \\
\hline I & 71 & 87 & & \\
\hline 2 & 22 & 26 & & \\
\hline 3 & 5 & 3 & & \\
\hline $\begin{array}{l}\text { Chemotherapy } \\
\text { cycles }\end{array}$ & $8.26 \pm 2.74$ & $9.78 \pm 2.32$ & 5.09 & 0.03 \\
\hline $\begin{array}{l}\text { CPT-I I initial } \\
\text { dosage (mg) }\end{array}$ & $293.60 \pm 30.28$ & $292.33 \pm 28.29$ & 0.82 & 0.37 \\
\hline $\begin{array}{l}\text { DPD activity } \\
(\mathrm{UH} 2 / \mathrm{U})\end{array}$ & $4.59 \pm 2.17$ & $4.83 \pm 1.86$ & 0.46 & 0.50 \\
\hline
\end{tabular}

Abbreviations: CPT-II, irinotecan; DPD, dihydropyrimidine dehydrogenase ECOG, East Cooperative Oncology Group; UGTIAI, uridine diphosphate glucuronosyltransferase IAI.

showing clear and stable bands in gel electrophoresis were mixed with $2 \mu \mathrm{L}$ of shrimp ALP (SAP) and then stored at $4^{\circ} \mathrm{C}$ after incubation at $37^{\circ} \mathrm{C}$ for 60 minutes and subsequent incubation at $80^{\circ} \mathrm{C}$ for 15 minutes. Approximately $3 \mu \mathrm{L}$ of positive PCR enzymatic hydrolysates, $1 \mu \mathrm{L}$ of sequencing reagent (BigDye ${ }^{\circledR}$; Applied Biosystems, Foster City, CA, USA), and 2 $\mu \mathrm{L}$ of sequencing primer containing fragments of UGT1A $1 * 28$ and UGT1A $1 * 6$ were used for PCR amplification. The primer pairs were designed and synthesized as follows: UGT1A1*28 primer: forward; 5'-CAGCCTCAAGACCCCACA-3', reverse: 5'-TGCTCCTGCCAGAGGTTC-3'; UGT1A1*6 primer: forward: 5'-TCCCTGCTACCTTTGTGGA-3', reverse: 5' AGGAAAGGGTCCGTCAGC-3'. PCR amplification was conducted in 25 cycles of denaturation at $96^{\circ} \mathrm{C}$ for 10 seconds, annealing at $50^{\circ} \mathrm{C}$ for 5 seconds, and extension at $60^{\circ} \mathrm{C}$ after an initial denaturation at $96^{\circ} \mathrm{C}$ for 1 minute; the temperature was maintained at $4^{\circ} \mathrm{C}$ after the reaction. Finally, the reaction products were directly sequenced with a DNA sequencer
(ABI-373; Thermo Fisher Scientific, Waltham, MA, USA), and the sequencing results were analyzed and displayed by FinchTV ${ }^{\circledR}$ software.

\section{DPD activity $\left(\mathrm{UH}_{2} / \mathrm{U}\right)$ determination}

The internal standard, composed of $250 \mu \mathrm{L}$ of plasma and $50 \mu \mathrm{L}$ of 5 -bromouracil (5-BrU) solution $(2 \mu \mathrm{g} / \mathrm{mL})$, was added to $1.5 \mathrm{~mL}$ extraction solution consisting of $n$-propanol: tert-butyl ether $(25: 75, v / v)$, and the mixture was vortexed for 2 minutes and centrifuged at $3,550 \times g$ for 5 minutes. The abovementioned steps were repeated after the organic phase was separated. The inorganic phase was dried with nitrogen and redissolved in $18 \mu \mathrm{L}$ of $\mathrm{ddH}_{2} \mathrm{O}$, and then $20 \mu \mathrm{L}$ of dichloromethane was added after vortex mixing for 30 seconds, followed by centrifugation at $2,250 \times \mathrm{g}$ for 10 minutes. After vortexing for 5 seconds, $10 \mu \mathrm{L}$ of the supernatant was injected into a high-performance liquid chromatography system. $\mathrm{UH}_{2} / \mathrm{U}$ detection was performed using the Shimadzu UFLC chromatographic system (Shimadzu Corporation, Kyoto, Japan), which was equipped with two LC-20AD pumps, a model DGU-20A3 degasser unit, an SIL-20A autosampler, a CTO-20AC thermosetted column compartment, and a model RF-10AXL fluorescence detector. Data were processed with Shimadzu LC-Solution chromatography software (version 1.21, SP1). Analytes were separated at room temperature using a Welch Ultimate XB-C18 column $(4.6 \times 150 \mathrm{~mm}$, $5 \mu \mathrm{m})$. Detection was carried out with $20 \mu \mathrm{L}$ of injection volume at an excitation wavelength of $385 \mathrm{~nm}$ and emission wavelength of $535 \mathrm{~nm}$ at a column temperature of $25^{\circ} \mathrm{C}$. The mobile phase consisted of acetonitrile: $0.05 \mathrm{M} \mathrm{Na}_{2} \mathrm{HPO}_{4}$ salt solution:triethylamine (72.5:27.5:0.5, v:v:v) with a flow rate at $1.0 \mathrm{~mL} / \mathrm{min}$ and was adjusted to $\mathrm{pH} 5.0$ by phosphate.

\section{Detection of plasma SN-38 levels}

SN-38 and internal standard were dissolved in 50\% methanol at a concentration of $1.0 \mathrm{mg} / \mathrm{mL}$ and stored at $-80^{\circ} \mathrm{C}$. To draw a calibration curve, an appropriate volume of standard working solution was added to $180 \mu \mathrm{L}$ aliquots of blank human plasma ranging from 5 to $1,500 \mathrm{ng} / \mathrm{mL}$. All samples were mixed with $100 \mu \mathrm{L}$ of $7 \%$ perchloric acid, vortexed for 3 minutes, and centrifuged at $15,800 \times g$ for 10 minutes. Plasma SN-38 levels were detected using the Shimadzu UFLC chromatographic system as described earlier. Data were processed with Shimadzu LC-Solution chromatography software (version 1.21, SP1).

\section{Evaluation and follow-up}

The first evaluation was conducted after three cycles of chemotherapy according to evaluation criteria for the curative effect of solid tumor (Response Evaluation Criteria in Solid 
Tumors, edition 1.1) for all patients. Efficacy reconfirmation was evaluated 4 weeks later for those who achieved complete or partial remission. ADRs were graded under the Common Terminology Criteria for Adverse Events version 3.0 (CTCAE v3.0). Patients could be administered other treatments such as second-line chemotherapy with or without molecular targeted drugs and best support care after progression and were visited every 3 months for survival analysis. The median follow-up time was 15 months (range, 8-22 months).

\section{Statistical methods}

The measurement data were presented as the mean $\pm \mathrm{SD}$, and the enumeration data were expressed as a rate or composition using SPSS ${ }^{\circledR}$ statistic software (version 19.0; IBM Corporation, Armonk, NY, USA). The Student's $t$-test was used for the measurement data such as plasma drug level comparison. Chi-squared test and one-way ANOVA were used for intergroup analysis of classification or connectivity evaluation index such as differences of ADRs. Kaplan-Meier test and Log-rank test were used to determine the differences in survival and efficacy between groups. A $P$-value $<0.05$ was considered to indicate significant results.

\section{Results}

\section{SNPs and proportion for UGTIAI*6 and/or $* 28$ heterozygous genotype}

The sequencing results are shown in Figure 1A-F for the 234 cases with the UGT1A $1 * 6$ and/or *28 heterozygous genotype (accounting for $46.89 \%$ ), including 116 cases of the $* 1 / * 1$ $* 1 / * 6$ genotype, 98 cases of the $* 1 / * 28-* 1 / * 1$ genotype, and 20 cases of the $* 1 / * 28-* 1 / * 6$ genotype. The constituent ratio is shown in Figure $1 \mathrm{G}$.

\section{$\mathrm{C}_{\mathrm{SN}-381.5 \mathrm{~h}}$ and $\mathrm{C}_{\mathrm{SN}-3849 \mathrm{~h}}$ between UGTIAI*6 and *28 wild-type and UGTIAI*6 and/or *28 heterozygous genotype}

As shown in Figure $2 \mathrm{~A}$, the $\mathrm{C}_{\mathrm{SN}-381.5 \mathrm{~h}}$ values of the $* 1 / * 28$ $* 1 / * 1$ and $* 1 / * 1-* 1 / * 6$ genotypes were $61.74 \pm 11.49$ and $63.10 \pm 10.29 \mathrm{ng} / \mathrm{mL}$, respectively, which were not significantly different from that of the $* 1 / * 1-* 1 / * 1$ genotype $(60.84 \pm 11.13 \mathrm{ng} / \mathrm{mL}, P=0.57$ and 0.13$)$, but were significantly lower than that of the $* 1 / * 28-* 1 / * 6$ genotype $(75.10 \pm 23.16 \mathrm{ng} / \mathrm{mL}, P<0.001)$. The same results were observed for $\mathrm{C}_{\mathrm{SN}-381.5 \mathrm{~h}}$ (Figure 2B).

Moreover, there were no significant differences in gender, age, ECOG performance status, location of the primary tumor, TMN staging, median of chemotherapeutic cycles, initial doses of CPT-11, and DPD activity between the $* 1 / * 28-* 1 / * 1$ and $* 1 / * 1-* 1 / * 6$ genotypes (Table 1 ).

\section{Regression analysis of $\mathrm{C}_{\mathrm{SN}-381.5 \mathrm{~h}}$ and $\mathrm{C}_{\mathrm{SN}-38}$ ${ }_{49 \mathrm{~h}}$ with clinical parameters}

Stepwise regression analysis was conducted for the $* 1 / * 28$ $* 1 / * 1$ and $* 1 / * 1-* 1 / * 6$ genotypes with $\mathrm{C}_{\mathrm{SN}-381.5 \mathrm{~h}}$ and $\mathrm{C}_{\mathrm{SN}-38}$ ${ }_{49 \mathrm{~h}}$ serving as dependent variables, and the initial doses of CPT-11, serum bilirubin levels before and after treatment, chemotherapeutic cycles, short-term response, PFS, overall survival (OS), and ADRs were independent variables. We found that $\mathrm{C}_{\mathrm{SN}-381.5 \mathrm{~h}}$ was related to PFS $(t=16.81, P<0.001)$, whereas $\mathrm{C}_{\mathrm{SN}-3849 \mathrm{~h}}$ was related to bone marrow hypocellularity, increased alanine aminotransferase, and diarrhea in the $* 1 / * 28-* 1 / * 1$ and $* 1 / * 1-* 1 / * 6$ genotypes $(t=8.82, P<0.001$; $t=5.02, P<0.001$; and $t=4.84, P<0.001$, respectively; Table 2 ).

\section{Median PFS (mPFS) of corresponding $\mathrm{C}_{\mathrm{SN}}$ - $381.5 \mathrm{~h}$ and $\mathrm{C}_{\mathrm{SN}-3849 \mathrm{~h}}$ subgroups in $* 1 / * 28$ - $* 1 / * 1$ and $* 1 / * 1-* 1 / * 6$ genotypes}

As shown in Figure 3 , the mPFS of the $* 1 / * 28-* 1 / * 1$, $* 1 / * 1-* 1 / * 6$, and $* 1 / * 28-* 1 / * 6$ genotypes were $6.73 \pm 0.13$, $6.73 \pm 0.18$, and $6.80 \pm 0.32$ months, respectively, with no significant difference between groups $\left(\chi^{2}=1.11, P=0.57\right)$. However, a comparison of the $\mathrm{C}_{\mathrm{SN}-381.5 \mathrm{~h}}>51.82 \mathrm{ng} / \mathrm{mL}$ and $\mathrm{C}_{\mathrm{SN}-3849 \mathrm{~h}}>14.34 \mathrm{ng} / \mathrm{mL}$ subsets with the $\leq 51.82$ and $\leq 14.34 \mathrm{ng} /$ $\mathrm{mL}$ subsets, respectively, grouped according to the adjusted predictive values and stand errors of the plasma SN-38 levels in the $* 1 / * 28-* 1 / * 1$ and $* 1 / * 1-* 1 / * 6$ genotypes revealed that the mPFS of the $\mathrm{C}_{\mathrm{SN}-381.5 \mathrm{~h}}>51.82 \mathrm{ng} / \mathrm{mL}$ subgroup was significantly longer than that of the $\leq 51.82 \mathrm{ng} / \mathrm{mL}$ subgroup (6.83 \pm 0.17 vs $4.87 \pm 0.13$ months, $6.93 \pm 0.34$ vs $5.63 \pm 0.31$ months; $P<0.001, P<0.001$ ), but no significant difference was observed in mPFS between the $\mathrm{C}_{\mathrm{SN}-3849 \mathrm{~h}}>14.34 \mathrm{ng} / \mathrm{mL}$ subgroup and $\leq 14.34 \mathrm{ng} / \mathrm{mL}$ subgroup $(6.83 \pm 0.48$ vs $6.63 \pm 0.13$ months, $7.27 \pm 0.35$ vs $6.70 \pm 0.21$ months, $P=0.80$ and $P=0.59$ ).

\section{ADRs between corresponding $\mathrm{C}_{\mathrm{SN}-38 \text { 1.5h }}$ and $\mathrm{C}_{\mathrm{SN}-3849 \mathrm{~h}}$ subgroups in $* 1 / * 28-* 1 / * 1$ and $* 1 / * 1-* 1 / * 6$ genotypes}

Given the relationship between $\mathrm{C}_{\mathrm{SN}-3849 \mathrm{~h}}$ and bone marrow hypocellularity in the $* 1 / * 28-* 1 / * 1$ and $* 1 / * 1-* 1 / * 6$ genotypes, the incidence of ADRs was compared between the $\mathrm{C}_{\mathrm{SN}-3849 \mathrm{~h}}>14.34$ and $\leq 14.34 \mathrm{ng} / \mathrm{mL}$ subgroups; the results showed that the incidence of bone marrow hypocellularity, diarrhea, increased alanine aminotransferase, nausea, and oral mucositis in the $\mathrm{C}_{\mathrm{SN}-3849 \mathrm{~h}}>14.34 \mathrm{ng} / \mathrm{mL}$ subgroup was 
A

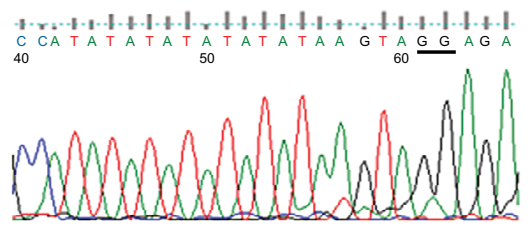

D
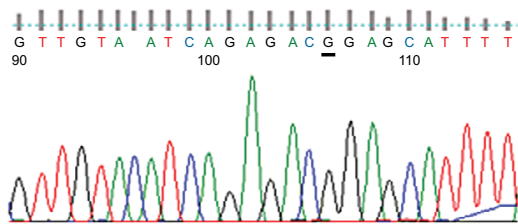

B

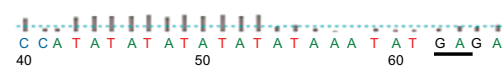

CATATATATA TH

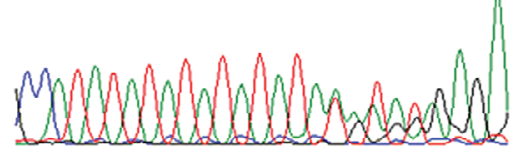

E

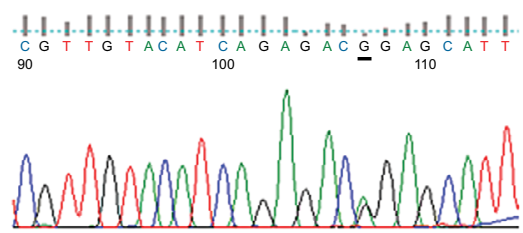

C

TTGC CA TA A A TA T ATA T ATA TA A G TA

40

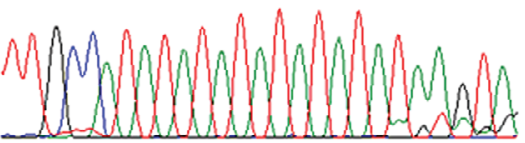

$\mathbf{F}$
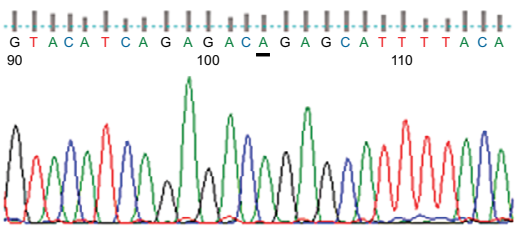

G

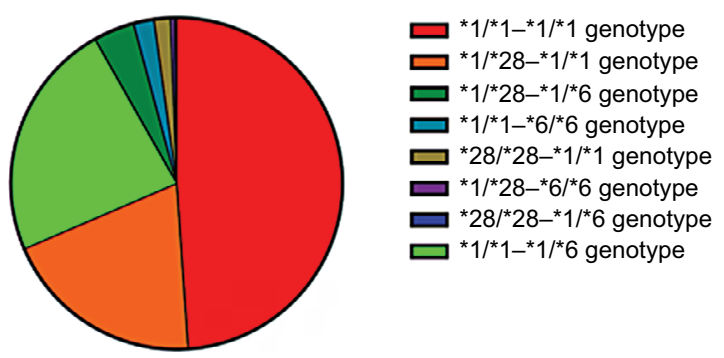

Figure I Sequencing results of UGTIAI*28 and *6 SNPs and distributive characteristics of different SNP combinations for mCRC patients.

Notes: DNA sequencing for wild-type UGTIAI*28 (A) and UGTIAI*6 (D), heterozygous type UGTIAI*28 (B) and UGTIAI*6 (E), and homozygous type UGTIAI*28 (C) and UGTIAI*6 (E) by FinchTV ${ }^{\circledR}$ software. (G) The pie chart gives the proportion of the different combinations of wild-type $(* 1 / * 1-* I / * I$ genotype: 244 cases, which accounted for $48.90 \%)$, heterozygous type $(* 1 / * 28-* 1 / * 1, * 1 / * 1-* 1 / * 6$, and $* 1 / * 28-* 1 / * 6$ genotype: 234 cases, which accounted for $46.89 \%)$, and heterozygous type $(* 28 / * 28-$ $* 1 / * 1, * 1 / * 1-* 6 / * 6, * 1 / * 28-* 6 / * 6$, and $* 28 / * 28-* 1 / * 6$ genotype: 21 cases, which accounted for only $4.21 \%)$.

Abbreviations: mCRC, metastatic colorectal cancer; SNP, single-nucleotide polymorphism; UGTIAI, uridine diphosphate glucuronosyltransferase IAI.

significantly higher than that in the $\leq 14.34 \mathrm{ng} / \mathrm{mL}$ subgroup $(P<0.001, P<0.001, P<0.001, P<0.001$, and $P<0.001)$; however, the difference between the $\mathrm{C}_{\mathrm{SN}-381.5 \mathrm{~h}}>51.82$ and $\leq 51.82$ $\mathrm{ng} / \mathrm{mL}$ subgroups was not significant $(P=0.04, P=0.24$, $P=0.97, P=0.12$, and $P=0.27 ; \mathrm{A}, \mathrm{B})$.

\section{DPD activities between $\mathrm{C}_{\mathrm{SN}-3849 \mathrm{~h}}>14.34$ and $\leq 14.34 \mathrm{ng} / \mathrm{mL}$ subgroups}

Comparison of the DPD activities between the $\mathrm{C}_{\mathrm{SN}-3849 \mathrm{~h}}>14.34$ and $\leq 14.34 \mathrm{ng} / \mathrm{mL}$ subgroups showed that the enzyme activities of the former were clearly lower than those of the latter (3.24 \pm 1.02 vs $4.93 \pm 2.08, F=11.20, P=0.001$; Figure $2 C$ ).

\section{mPFS of DPD activities between $>4.13$ and $\leq 4.13$ subsets in $C_{S N-3849 h}>14.34$ and $\leq 14.34 \mathrm{ng} / \mathrm{mL}$ subgroups}

By setting DPD activities as dependent variables and clinical parameters such as short-term response, PFS, OS, and ADRs as independent variables, stepwise regression indicated that DPD activities were related to the bone marrow hypocellularity and increased alanine aminotransferase $(t=-3.03$ and $t=-2.75, P=0.003$ and $P=0.007$; Table 2), and the mPFS of DPD activities of the $>4.13$ and $\leq 4.13$ subsets divided based on the adjusted predictive values and stand errors did not greatly differ in the $\mathrm{C}_{\mathrm{SN}-3849 \mathrm{~h}}>14.34 \mathrm{ng} / \mathrm{mL}$ subgroup ( $6.83 \pm 0.33$ vs $7.27 \pm 0.53$ months, $\chi^{2}=0.07, P=0.85$; Figure 3 ).

\section{Discussion}

Dosage individualization of chemotherapeutic drugs is an important factor in personalized cancer treatment, and it has been widely acknowledged in mCRC that CPT-11-associated life-threatening ADRs can be avoided by screening out the UGT1A1 homozygous genotype before administration of CPT-11-based chemotherapy; ${ }^{14,15}$ however, meta-analysis and studies did not confirm the relationship between the UGT1A $1 * 6$ and $* 28$ genotypes and clinical outcomes, ${ }^{3,16-19}$ but individual dose adjustment is difficult based only on the UGT1A1 genotype. Moreover, most Asian populations have wild-type UGT1A1 or a heterozygous genotype, and the risks of CPT-11-associated serious ADRs are much lower than those for the homozygous genotype according to some meta-analyses, as $\mathrm{SN}-38$ glucuronidation of the former two has been completely saturated. ${ }^{20}$ Therefore, the main purpose of personalized CPT-11 administration is to 

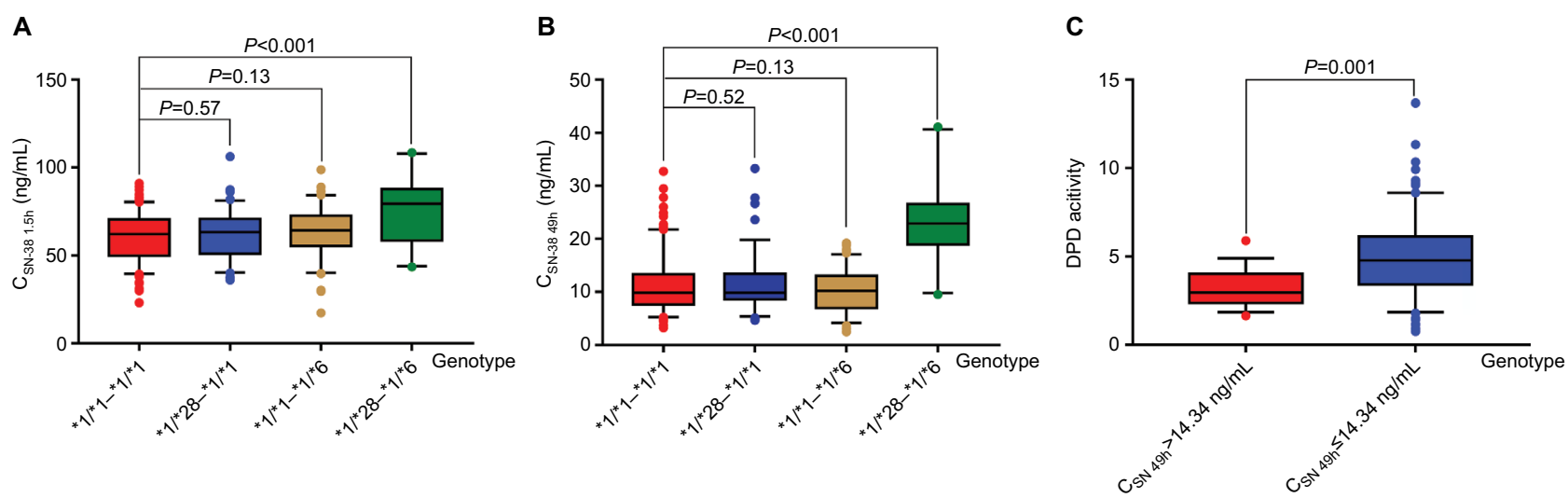

Figure $2 \mathrm{C}_{\mathrm{SN}-381.5 \mathrm{~h}}$ and $\mathrm{C}_{\mathrm{SN}-3849 \mathrm{~h}}$ between UGTIAI*6 and $* 28$ wild-type and UGTIAI*6 and $* 28$ heterozygous genotype as well as DPD activities between $\mathrm{C}_{\mathrm{SN}-3849 \mathrm{~h}}>$ I4.34 $\mathrm{ng} / \mathrm{mL}$ and $\leq 14.34 \mathrm{ng} / \mathrm{mL}$ subgroups.

Notes: The $C_{5 N-381.5 \mathrm{~h}}$ of $* 1 / * 1-* 1 / * I$ genotype was $60.84 \pm 11.13 \mathrm{ng} / \mathrm{mL}$, having no significant difference with those of $* 1 / * 28-* 1 / * I$ and $* 1 / * I-* 1 / * 6$ genotype $(61.74 \pm I I .49$ and $63.10 \pm 10.29 \mathrm{ng} / \mathrm{mL}, P=0.57$ and 0.13 , respectively), but with statistical difference being found in that of $* 1 / * 28-* 1 / * 6$ genotype $(75.10 \pm 23.16 \mathrm{ng} / \mathrm{mL}, P<0.001$, seen in $\mathbf{A})$. Likewise in $\mathrm{C}_{5 \mathrm{~N}-3849 \mathrm{~g}}$, the $\mathrm{C}_{5 \mathrm{SN}-3849 \mathrm{~h}}$ of $* 1 / * 28-* 1 / * 1$ and $* 1 / * 1-* 1 / * 6$ genotype were II.49 \pm 5.06 and $10.29 \pm 3.70 \mathrm{ng} / \mathrm{mL}$, respectively, which did not differ obviously from that of $* I / * I-* 1 / * I$ genotype $(1 \mathrm{I} .13 \pm 4.95 \mathrm{ng} / \mathrm{mL}, P=0.52$ and 0.13$)$, while being significantly different from that of $* \mathrm{I} / * 28-* \mathrm{I} / * 6$ genotype $(23.16 \pm 6.95 \mathrm{ng} / \mathrm{mL}, P<0.00 \mathrm{I}$, shown in $\mathbf{B})$. In C, the DPD activity of $C_{S N-3849 h}>14.34 \mathrm{ng} / \mathrm{mL}$ subgroup was $3.24 \pm 1.02$, remarkably lower than that of $C_{S N-3849 h} \leq 14.34 \mathrm{ng} / \mathrm{mL}$ subgroup with obvious difference (4.93 \pm 2.08 , $F=I I .20, P=0.00 I)$.

Abbreviations: CPT-I I, irinotecan; $\mathrm{C}_{\mathrm{SN}-38 \text { I.5h, }}$, lasma SN-38 level I.5 hours after CPT-II administration; $\mathrm{C}_{\mathrm{SN}-3849 \mathrm{~h}}$ plasma SN-38 level 49 hours after CPT-II administration; DPD, dihydropyrimidine dehydrogenase; UGTIAI, uridine diphosphate glucuronosyltransferase IAI.

Table 2 Stepwise regression of $\mathrm{C}_{\mathrm{SN}-381.5 \mathrm{~h}}, \mathrm{C}_{\mathrm{SN}-3849 \mathrm{~h}}$, and DPD activity for $* 1 / * 28-* \mathrm{I} / * \mathrm{I}$ and $* \mathrm{I} / * \mathrm{I}-* \mathrm{I} / * 6$ genotypes

\begin{tabular}{|c|c|c|c|c|c|c|c|}
\hline & \multirow[t]{2}{*}{ Associated clinical parameters } & \multicolumn{2}{|l|}{$95 \% \mathrm{Cl}$} & \multirow[t]{2}{*}{$\boldsymbol{t}$} & \multirow[t]{2}{*}{$P$-value } & \multirow{2}{*}{$\begin{array}{l}\text { Mean of adjusted } \\
\text { predicted value }\end{array}$} & \multirow{2}{*}{$\begin{array}{l}\text { Standard error of } \\
\text { predicted value }\end{array}$} \\
\hline & & Lower & Upper & & & & \\
\hline \multirow{2}{*}{$\mathrm{C}_{\mathrm{SN}-381.5 \mathrm{~h}}(\mathrm{ng} / \mathrm{mL})$} & Constant & 20.21 & 29.36 & & & \multirow[t]{2}{*}{62.51} & \multirow[t]{2}{*}{10.69} \\
\hline & PFS & 5.77 & 7.30 & 16.81 & $<0.001$ & & \\
\hline \multirow[t]{4}{*}{$\mathrm{C}_{\mathrm{SN}-3849 \mathrm{~h}}(\mathrm{ng} / \mathrm{mL})$} & Constant & 6.34 & 7.66 & 20.92 & & \multirow[t]{4}{*}{10.84} & \multirow[t]{4}{*}{3.50} \\
\hline & Bone marrow hypocellularity & 2.14 & 3.37 & 8.82 & $<0.001$ & & \\
\hline & Increased alanine aminotransferase & 1.19 & 2.73 & 5.02 & $<0.001$ & & \\
\hline & Diarrhea & 1.37 & 3.24 & 4.84 & $<0.001$ & & \\
\hline \multirow[t]{3}{*}{ DPD activity } & Constant & 4.89 & 5.75 & 24.20 & & \multirow[t]{3}{*}{4.66} & \multirow[t]{3}{*}{0.53} \\
\hline & Bone marrow hypocellularity & -1.23 & -0.20 & -2.75 & 0.007 & & \\
\hline & Increased alanine aminotransferase & -0.81 & -0.17 & -3.03 & 0.003 & & \\
\hline
\end{tabular}

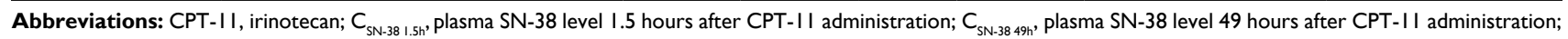
DPD, dihydropyrimidine dehydrogenase; PFS, progression-free survival.

improve the therapeutic effect by dosage adjustment based on SN-38 pharmacokinetics. The MTD restricts dose escalation because of the factors such as the dose increase extent, escalation intervals, and patients' compliance, leading to different subclinical doses administered to patients and distress in judging the outcomes of CPT-11. Accordingly, it is necessary to take $\mathrm{SN}-38$ pharmacokinetics into account when the correlation between different genotypes and outcomes are evaluated, particularly for the heterozygous genotype, which accounts for a large proportion of patients and shows variable UGT1A1 activities. ${ }^{5,21}$

Previous studies of pharmacokinetics showed that the plasma CPT-11 levels reached a peak at 1.5 hours and decreased to minimum levels at 25.5 hours after intravenous
CPT-11 infusion, ${ }^{22}$ and thus, the plasma SN-38 levels at 1.5 and 49 hours after CPT-11 infusion were evaluated to reflect the metabolism of CPT- 11 in this study to examine CPT-11 dose individualization over a relatively short period. It is difficult to determine MTD by computing the $\mathrm{AUC}^{8,23}$ because of factors such as repeated blood sampling, high cost of the examination, long submission cycle, difficult promotion, and poor compliance of patients. Our results showed that the $\mathrm{C}_{\mathrm{SN}-381.5 \mathrm{~h}}$ and $\mathrm{C}_{\mathrm{SN}-3849 \mathrm{~h}}$ of the $* 1 / * 28-* 1 / * 1$ and $* 1 / * 1-* 1 / * 6$ genotypes were close to that of the $* 1 / * 1-* 1 / * 1$ genotype, but significantly lower than that of the $* 1 / * 28-* 1 / * 6$ genotype (as shown in Figure 2), indicating that the UGT1A1 activities of the $* 1 / * 28-* 1 / * 1$ and $* 1 / * 1-* 1 / * 6$ genotypes were similar to that of the $* 1 / * 1-* 1 / * 1$ genotype. Thus, we 

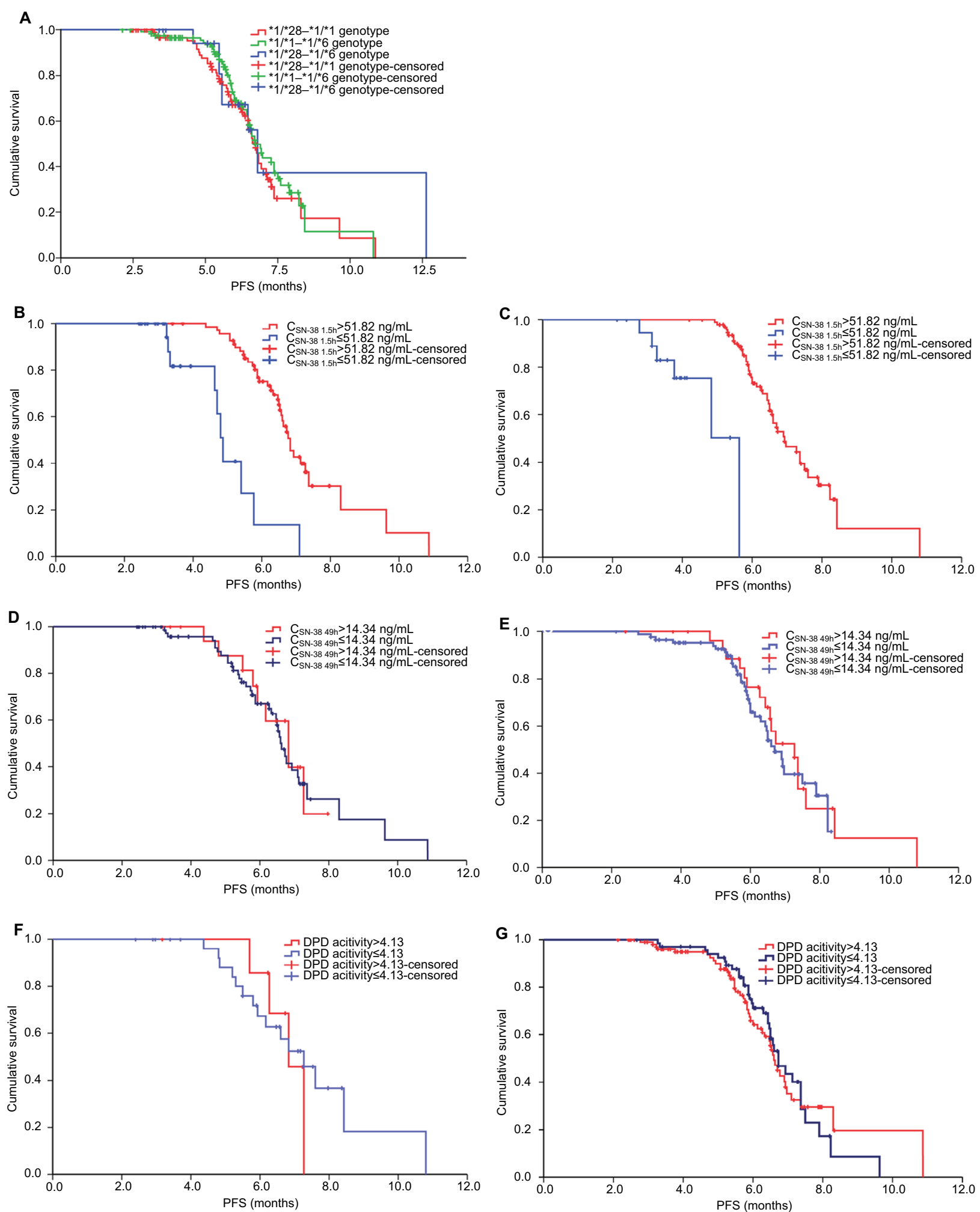

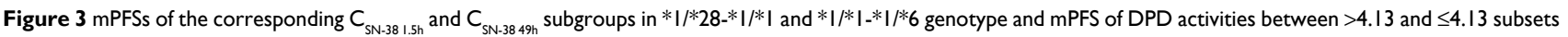
in $\mathrm{C}_{\mathrm{SN}-3849 \mathrm{~h}}>14.34 \mathrm{ng} / \mathrm{mL}$ and $\leq 14.34 \mathrm{ng} / \mathrm{mL}$ subgroups, respectively, accordingly.

Notes: No statistical difference was observed about the mPFS among $* 1 / * 28-* 1 / * 1, * 1 / * 1-* 1 / * 6$, and $* 1 / * 28-* 1 / * 6$ genotypes $(\mathbf{A})(6.73 \pm 0.13$ months vs $6.73 \pm 0.18$ months vs $6.80 \pm 0.32$ months, $\chi^{2}=1.11, P=0.57$ ), but differences were displayed clearly between the mPFS of $C_{5 N-381.5 n}>51.82 \mathrm{ng} / \mathrm{mL}$ and that of $\leq 51.82 \mathrm{ng} / \mathrm{mL}$ subgroup in $* 1 / * 28-* 1 / * 1$ (B) and $* I / * I-* 1 / * 6$ genotypes $($ C) $(6.83 \pm 0.17$ vs $4.87 \pm 0.13$ months, $P<0.001 ; 6.93 \pm 0.34$ vs $5.63 \pm 0.3 \mathrm{I}$ months, $P<0.00 \mathrm{I})$, which were divided by the adjusted predictive values and stand errors of $C_{\mathrm{SN}-381.5 \mathrm{~h}}$, while the mPFS did not differ between $\mathrm{C}_{\mathrm{SN}-3844 \mathrm{~h}}>14.34 \mathrm{ng} / \mathrm{mL}$ and $\leq 14.34 \mathrm{ng} / \mathrm{mL}$ subgroups grouped by the same way in $* 1 / * 28-* 1 / * 1$ (D) and $* 1 / * 1-* 1 / * 6$ genotypes $(E)(6.83 \pm 0.48$ vs $6.63 \pm 0.13$ months, $P=0.80 ; 7.27 \pm 0.35$ vs $6.70 \pm 0.21$ months, $P=0.59)$. The mPFS of DPD activities $>4.13$ and $\leq 4.13$ subset divided based on the adjusted predictive values and stand errors did not differ obviously in $C_{5 \mathrm{~N}-38} 44 \mathrm{~h} / 4.34 \mathrm{ng} / \mathrm{mL}$ and $\leq 14.34 \mathrm{ng} / \mathrm{mL}$ subgroups of $* 1 / * 28-* 1 / * 1(\mathbf{F})$ and $* 1 / * 1-* 1 / * 6$ genotypes (G) (6.83 \pm 0.33 vs $7.27 \pm 0.53$ months, $\chi^{2}=0.04, P=0.85 ; 6.60 \pm 0.12$ vs $6.73 \pm 0.22$ months, $\left.\chi^{2}=0.07, P=0.79\right)$.

Abbreviations: CPT- I I, irinotecan; $\mathrm{C}_{\mathrm{SN}-38}$ I.5h, plasma SN-38 level I.5 hours after CPT-I I administration; $\mathrm{C}_{\mathrm{SN}-3849 \mathrm{~h}}$, 1 lasma SN-38 level 49 hours after CPT-II administration; DPD, dihydropyrimidine dehydrogenase; mPFS, median PFS; PFS, progression-free survival. 


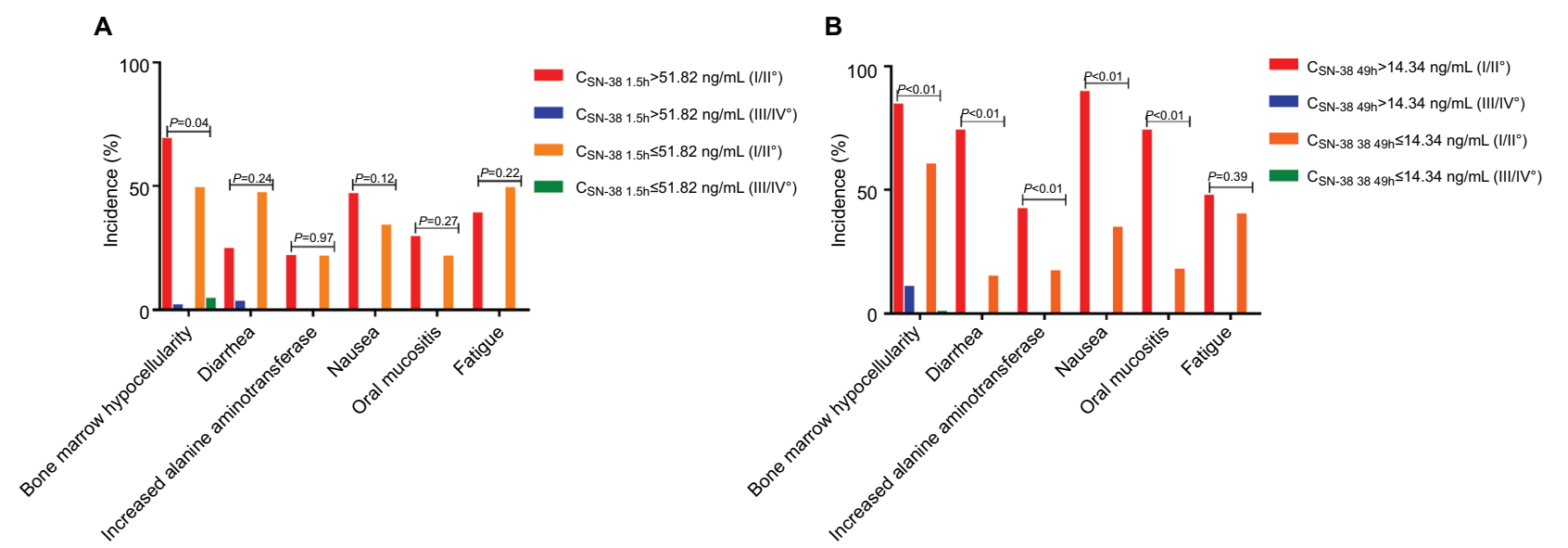

Figure 4 ADRs between corresponding $C_{S N-381.5 \mathrm{~h}}$ and $C_{S N-3849 h}$ subgroups in *I/*28-*I/*I and *I/*I-*I/*6 genotypes.

Notes: It was not significantly distinguished between $C_{S N-381.5 \mathrm{~h}}>5 \mathrm{I} .82 \mathrm{ng} / \mathrm{mL}$ and $\leq 5 \mathrm{I} .82 \mathrm{ng} / \mathrm{mL}$ subgroups $(\mathbf{A})(F=6.58, P=0.04 ; F=2.86, P=0.24 ; F=0.002, P=0.97 ; F=2.39, P=0.12 ;$ and $F=1.20, P=0.27$ ). However, the incidence of bone marrow hypocellularity, diarrhea, increased alanine aminotransferase, nausea, and oral mucositis in $C_{S N-38} 49 \mathrm{~h}>14.34 \mathrm{ng} /$ $\mathrm{mL}$ subgroup was higher than that in $\leq 14.34 \mathrm{ng} / \mathrm{mL}$ subgroup with statistical difference $(B)(F=26.09, P<0.00 I ; F=57.92, P<0.00 I ; F=I I .63, P<0.00 I ; F=38.04, P<0.00 I ;$ and $F=49.20, P<0.01$ ). ADRs were graded by CTCAE $\vee 4.03$.

Abbreviations: ADR, adverse reaction; CPT-II, irinotecan; CTCAE, Common Terminology Criteria for Adverse Events; $\mathrm{C}_{\mathrm{SN}-38 \text { I.5h }}$, plasma SN-38 level I.5 hours after CPT-

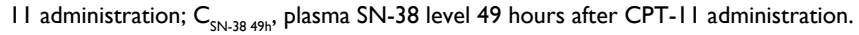

selected the $* 1 / * 28-* 1 / * 1$ and $* 1 / * 1-* 1 / * 6$ genotypes for retrospective analysis because of the relatively low risk of ADRs for dose personalized adjustment of CPT-11. Table 1 shows that the clinical characteristics of the two genotypes were comparable in combined analysis, and stepwise regression analysis revealed that $\mathrm{C}_{\mathrm{SN}-381.5 \mathrm{~h}}$ was relevant to PFS and $\mathrm{C}_{\mathrm{SN}-3849 \mathrm{~h}}$ was associated with ADRs such as bone marrow hypocellularity. Further analysis indicated that the mPFS of the $\mathrm{C}_{\mathrm{SN}-381.5 \mathrm{~h}}>51.82 \mathrm{ng} / \mathrm{mL}$ subgroup was significantly longer than that of the $\leq 51.82 \mathrm{ng} / \mathrm{mL}$ subgroup, whereas no difference of mPFS was observed between the $\mathrm{C}_{\mathrm{SN}-3849 \mathrm{~h}}>14.34$ and $\leq 14.34 \mathrm{ng} / \mathrm{mL}$ subgroups, suggesting that the efficacy can be improved by increasing the CPT-11 dose while monitoring $\mathrm{C}_{\mathrm{SN}-381.5 \mathrm{~h}}$ in the $\mathrm{C}_{\mathrm{SN}-381.5 \mathrm{~h}} \leq 51.82 \mathrm{ng} / \mathrm{mL}$ subgroup.

For ADRs, we found no significant difference between the $\mathrm{C}_{\mathrm{SN}-381.5 \mathrm{~h}}>51.82$ and $\leq 51.82 \mathrm{ng} / \mathrm{mL}$ subgroups; however, the ADRS incidence in the $\mathrm{C}_{\mathrm{SN}-3849 \mathrm{~h}}>14.34 \mathrm{ng} / \mathrm{mL}$ subgroup was significantly higher than that in the $\leq 14.34 \mathrm{ng} / \mathrm{mL}$ subgroup. Although a previous study indicated that 5-FU did not change the metabolic process of CPT- 11 within a regular dose range,${ }^{24}$ the determination of CPT-11-associated ADRs can be affected because similar 5-FU-correlated ADRs are caused by decreased or inhibited DPD activities. To evaluate the high incidence of ADRs in the $\mathrm{C}_{\mathrm{SN}-3849 \mathrm{~h}}>14.34 \mathrm{ng} / \mathrm{mL}$ subgroup, stepwise regression was conducted, which showed that when DPD activities were correlated with bone marrow hypocellularity and increased alanine aminotransferase, the DPD activities of $\mathrm{C}_{\mathrm{SN}-3849 \mathrm{~h}}>14.34 \mathrm{ng} / \mathrm{mL}$ subset were remarkably lower than that of the $\leq 14.34 \mathrm{ng} / \mathrm{mL}$ subset; however, there was no significant difference in MPFS between the DPD activities $>4.13$ subset and $\leq 4.13$ subset (Figure $2 \mathrm{C}$ ), indicating that 5-FU-associated ADRs due to decreased activities of DPD were misclassified as CPT-11-related ADRs caused by reduced UGT1A1 activities. This leads to mistaken downregulation of the CPT-11 dose, and thus, the activity or SNPs of DPD must be determined before adjusting the 5-FU dosage before CPT-11-based chemotherapy. In addition, reducing the doses of 5-FU did not affect the outcomes.

Subsequent dose individualization of CPT-11 and its effect on outcomes require further analysis via plasma 5-FU levels monitoring, improving the stability and repeatability of the method to detect the plasma SN-38 levels, and conducting prospective randomized controlled studies with larger samples. In addition, other biomarkers such as members of the ATP-Binding Cassette Subfamily C (ABCC), ${ }^{25-27}$ organic anion-transporting polypeptide $1 \mathrm{~B} 1,{ }^{28,29}$ and other factors including obesity ${ }^{30}$ and human organ function ${ }^{31,32}$ require further analysis to identify better biomarkers or combinations of biomarkers for predicting the efficacy and/or ADRs of CPT-11-based chemotherapy.

\section{Conclusion}

According to our analyses, a dose increase of CPT-11 based on $\mathrm{C}_{\mathrm{SN}-381.5 \mathrm{~h}}$ may improve the efficacy in patients with lower $\mathrm{C}_{\mathrm{SN}-381.5 \mathrm{~h}}$ levels. For cases with relatively low DPD activity, advisable primary and subsequent dose adjustment of 5-FU based on the plasma 5-FU levels may be a practical strategy for reducing the incidence of 5-FU-associated ADRs for 
individualized administration of CPT-11 to those with the UGT1A $1 * 6$ or $* 28$ heterozygous type.

\section{Ethics approval and consent to participate}

The plan of the research has taken full consideration in the principles of safety and fairness and would be risk free to the patients. This article does not contain any studies with human participants or animals performed by any of the authors. The investigator would protect the patients' rights and privacy to the maximum extent and make sure that there were no conflicts of interest between the contents and the results of the research. Although no formal consent is required for this type of retrospective research, to ensure the implementation of the project, the patients were admitted to the study providing that they come across this principle of "Ethics, consent and permissions". Before the plasma specimen being collected, the patients were fully informed as follows: the purposes and methods of the study, the plasma specimen as part of the context, the project would not increase the extra medical costs and pain of patients, and the materials and results of the study were used for the purposes of scientific research without conflict of interest. Any report and publication of the individual patient data (in the form of images, videos, voice recordings, etc) needed the approval of the patients enrolled in the study.

\section{Acknowledgments}

The authors thank pharmacists Guanhua Zhu, Shengying Gu, and Yankun Guo from the Department of Clinical Pharmacy of Shanghai General Hospital for the detection of polymorphisms of UGT1A1 *28 and *6, plasma SN-38 levels, and DPD activities; and Doctor Mei Kang (statistician) from the Clinical Trial Institution of Shanghai General Hospital for statistical work.

\section{Author contributions}

This work was completed with the cooperation of all authors. Xun Cai and Rongyuan Zhuang defined the research objective. Xun Cai, Chuan Tian, and Haifeng Ying designed methods and experiments, carried out the laboratory experiments, analyzed the data, interpreted the results, and wrote the manuscript. Rongyuan Zhuang, Haifeng Ying, Xiaowei Zhang, Hongmin Lu, Hui Wang, Qi Li, and Chungang Wang worked together on patient screening and associated data collection, and Shuowen Wang provided guidance on the pharmacokinetic tests. All authors contributed toward data analysis, drafting and critically revising the paper, gave final approval of the version to be published, and agree to be accountable for all aspects of the work.

\section{Disclosure}

The authors report no conflicts of interest in this work.

\section{References}

1. Deeken JF, Figg WD, Bates SE, Sparreboom A. Toward individualized treatment: prediction of anticancer drug disposition and toxicity with pharmacogenetics. Anticancer Drugs. 2007;18(2):111-126.

2. Lee W, Lockhart AC, Kim RB, Rothenberg ML. Cancer pharmacogenomics: powerful tools in cancer chemotherapy and drug development. Oncologist. 2005;10(2):104-111.

3. Onoue M, Terada T, Kobayashi M, et al. UGT1A1*6 polymorphism is most predictive of severe neutropenia induced by irinotecan in Japanese cancer patients. Cancer Chemother Pharmacol. 2014;14(2):136-142.

4. Hu ZY, Yu Q, Pei Q, Guo C. Dose-dependent association between UGT1A $1 * 28$ genotype and irinotecan-induced neutropenia: low doses also increase risk. Clin Cancer Res. 2010;16(15):3832-3842.

5. Jada SR, Lim R, Wong CI, et al. Role of UGT1A1*6, UGT1A1*28 and ABCG2 c. $421 \mathrm{C}>\mathrm{A}$ polymorphisms in irinotecan-induced neutropenia in Asian cancer patients. Cancer Sci. 2007:98(9):1461-1467.

6. Wang Y, Xu JM, Shen L, et al. Polymorphisms of UGT1A gene and irinotecan toxicity in Chinese colorectal cancer patients. Zhonghua Zhong Liu Za Zhi. 2007:29(12):913-916. Chinese.

7. Patel JN, Papachristos A.Personalizing chemotherapy dosing using pharmacological methods. Cancer Chemother Pharmacol. 2015;76(5):879-896.

8. Innocenti F, Schilsky RL, Ramírez J, et al. Dose-finding and pharmacokinetic study to optimize the dosing of irinotecan according to the UGT1A1 genotype of patients with cancer. J. Clin Oncol. 2014;32(22):2328-2334.

9. Toffoli G, Sharma MR, Marangon E, et al. Genotype-guided dosing study of FOLFIRI plus bevacizumab in patients with metastatic colorectal cancer. Clin Cancer Res. 20017:23(4):918-924.

10. Cai X, Cao W, Ding H, et al. Analysis of UGT1A1*28 genotype and SN-38 pharmacokinetics for irinotecan-based chemotherapy in patients with advanced colorectal cancer: results from a multicenter, retrospective study in Shanghai. J Cancer Res Clin Oncol. 2013:139(9):1579-1589.

11. Cai X, Tian C, Wang L, et al. Correlative analysis of plasma SN-38 levels and DPD activity with outcomes of FOLFIRI regimen for metastatic colorectal cancer with UGT1A1*28 and *6 wild type and its implication for individualized chemotherapy. Cancer Biol Ther. 2017;18(3):186-193.

12. Maring JG, van Kuilenburg AB, Haasjes J, et al. Reduced 5-FU clearance in a patient with low DPD activity due to heterozygosity for a mutant allele of the DPYD gene. Br J Cancer. 2002;86(7):1028-1033.

13. Falvella FS, Cheli S, Martinetti A, et al. DPD and UGT1A1 deficiency in colorectal cancer patients receiving triplet chemotherapy with fluoropyrimidines, oxaliplatin and irinotecan. $\mathrm{Br} J$ Clin Pharmacol. 2015;80(3):581-588.

14. Schmoll HJ, Van Cutsem E, Stein A, et al. ESMO Consensus Guidelines for management of patients with colon and rectal cancer. a personalized approach to clinical decision making. Ann Oncol. 2012;23(10):2479-2516.

15. Watanabe T, Itabashi M, Shimada Y, et al.; Japanese Society for Cancer of the Colon and Rectum. Japanese Society for Cancer of the Colon and Rectum (JSCCR) Guidelines 2014 for treatment of colorectal cancer. Int J Clin Oncol. 2015;20(2):207-239.

16. Satoh T, Ura T, Yamada Y, et al. Genotype-directed, dose-finding study of irinotecan in cancer patients with UGT1A1*28 and/or UGT1A1*6 polymorphisms. Cancer Sci. 2011;102(10):1868-1873.

17. Liu X, Cheng D, Kuang Q, Liu G, Xu W. Association between UGT1A1*28 polymorphisms and clinical outcomes of irinotecan-based chemotherapies in colorectal cancer: a meta-analysis in Caucasians. PLoS One. 2013;8(3):e58489.

18. Dias MM, Pignon JP, Karapetis CS, et al. The effect of the UGT1A1*28 allele on survival after irinotecan-based chemotherapy: a collaborative meta-analysis. Pharmacogenomics J. 2014;14(5):424-431.

19. Takano M, Sugiyama T2. UGT1A1 polymorphisms in cancer: impact on irinotecan treatment. Pharmgenomics Pers Med. 2017;10:61-68. 
20. Ichikawa W, Araki K, Fujita K, et al. Re: UGT1A1*28 genotype and irinotecan-induced neutropenia: dose matters. J Natl Cancer Inst. 2008;100(3):224-225; author reply 225.

21. Zhang A, Xing Q, Qin S, et al. Intra-ethnic differences in genetic variants of the UGT-glucuronosyltransferase 1A1 gene in Chinese populations. Pharmacogenomics J. 2007;7(5):333-338.

22. Sumiyoshi H, Fujiwara Y, Ohune T, Yamaoka N, Tamura K, Yamakido M. High-performance liquid chromatographic determination of irinotecan (CPT-11) and its active metabolite (SN-38) in human plasma. $J$ Chromatogr B Biomed Appl. 1995;670(2):309-316.

23. Kim KP, Hong YS, Lee JL, et al. A phase I study of UGT1A1*28/*6 genotype-directed dosing of irinotecan (CPT-11) in Korean patients with metastatic colorectal cancer receiving FOLFIRI. Oncology. 2015;88(3):164-172.

24. Ducreux M, Ychou M, Seitz JF, et al. Irinotecan combined with bolus fluorouracil, continuous infusion fluorouracil, and high-dose leucovorin every two weeks (LV5FU2 regimen): a clinical dose-finding and pharmacokinetic study in patients with pretreated metastatic colorectal cancer. J Clin Oncol. 1999;17(9):2901-2908.

25. Mathijssen RH, Marsh S, Karlsson MO, et al. Irinotecan pathway genotype analysis to predict pharmacokinetics. Clin Cancer Res. 2003;15;9(9):3246-3253.
26. Sai K, Kaniwa N, Itoda M, et al. Haplotype analysis of ABCB1/MDR1 blocks in a Japanese population reveals genotype-dependent renal clearance of irinotecan. Pharmacogenetics. 2003;13(12):741-757.

27. Kitamura Y, Kusuhara H, Sugiyama Y. Functional characterization of multidrug resistance-associated protein 3 ( $\mathrm{mrp} 3 / \mathrm{abcc} 3)$ in the basolateral efflux of glucuronide conjugates in the mouse small intestine. $J$ Pharmacol Exp Ther. 2010;332(2):659-666.

28. Iusuf D, van de Steeg E, Schinkel AH. Hepatocyte hopping of OATP1B substrates contributes to efficient hepatic detoxification. Clin Pharmacol. Ther. 2012:92(5):559-562.

29. Teft WA, Welch S, Lenehan J, et al. OATP1B1 and tumour OATP1B3 modulate exposure, toxicity, and survival after irinotecan-based chemotherapy. Br J Cancer. 2015;112(5):857-865.

30. Phelps MA, Sparreboom A. Irinotecan pharmacogenetics: a finished puzzle? J Clin Oncol. 2014;32(22):2287-2289.

31. Schaaf LJ, Hammond LA, Tipping SJ, et al. Phase 1 and pharmacokinetic study of intravenous irinotecan in refractory solid tumor patients with hepatic dysfunction. Clin Cancer Res. 2006;12(12):3782-3791.

32. Fujita K, Sunakawa Y, Miwa K, et al. Delayed elimination of SN-38 in cancer patients with severe renal failure. Drug Metab Dispos. 2011;39(2): $161-164$.
Cancer Management and Research

\section{Publish your work in this journal}

Cancer Management and Research is an international, peer-reviewed open access journal focusing on cancer research and the optimal use of preventative and integrated treatment interventions to achieve improved outcomes, enhanced survival and quality of life for the cancer patient. The manuscript management system is completely online and includes
Dovepress

a very quick and fair peer-review system, which is all easy to use. Visit http://www.dovepress.com/testimonials.php to read real quotes from published authors. 